\title{
Indirect Sliding Mode Control for DC-DC SEPIC Converters
}

\author{
Hasan Komurcugil \\ Eastern Mediterranean University,Via Mersin 10, Turkey, hasan.komurcugil@emu.edu.tr \\ Samet Biricik \\ Technological University Dublin, sbiricik@eul.edu.tr \\ Naki Guler \\ Gazi University Ankara, nakiguler@gazi.edu.tr
}

Follow this and additional works at: https://arrow.tudublin.ie/engscheleart2

Part of the Electrical and Computer Engineering Commons

\section{Recommended Citation}

H. Komurcugil, S. Biricik and N. Guler, "Indirect Sliding Mode Control for DC-DC SEPIC Converters," in IEEE Transactions on Industrial Informatics, vol. 16, no. 6, pp. 4099-4108, June 2020, doi: 10.1109/ TII.2019.2960067.

This Article is brought to you for free and open access by the School of Electrical and Electronic Engineering at ARROW@TU Dublin. It has been accepted for inclusion in Articles by an authorized administrator of ARROW@TU Dublin. For more information, please contact arrow.admin@tudublin.ie, aisling.coyne@tudublin.ie, gerard.connolly@tudublin.ie.

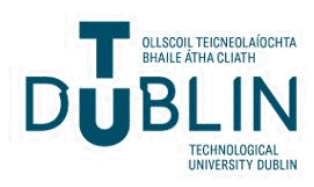




\title{
Indirect Sliding Mode Control for DC-DC SEPIC Converters
}

\author{
Hasan Komurcugil ${ }^{\odot}$, Senior Member, IEEE, Samet Biricik ${ }^{\circledR}$, Senior Member, IEEE, and Naki Guler ${ }^{\circledR}$
}

\begin{abstract}
This article presents an indirect sliding mode control (SMC) for single-ended primary-inductor converters (SEPIC). Unlike the conventional SMC methods, the proposed SMC method employs a sliding surface function based on the input current error only. The use of such sliding surface function not only simplifies the implementation but also reduces the cost of implementation. It is shown that the output voltage control can be achieved indirectly. The input current reference is generated by a proportionalintegral $(\mathrm{PI})$ regulator. The existence condition and the region of the closed-loop system are determined for all possibilities of the PI gains. The performance of the proposed SMC method is investigated on a laboratory prototype converter, operated in buck and boost modes, in terms of the voltage regulation ability under abrupt changes in the input voltage and load resistance. Simulation and experimental results are presented and discussed.
\end{abstract}

Index Terms-Proportional-integral (PI) control, singleended primary-inductor converter (SEPIC), sliding mode control (SMC).

\section{INTRODUCTION}

D C-DC converters are power electronics devices that are widely used in many applications including dc motor drives, communication equipment, and power supplies for personal computers [1]. Among the dc-dc converters, Cuk [2]-[4] and single-ended primary-inductor converters (SEPIC) [5]-[10] are widely used in applications where low ripple current is desired at the input and output terminals of the converter. These converters with step-down and step-up capabilities are suitable in the off-grid photovoltaic (PV) applications due to their interconnection ability with different batteries and PV modules. The inverse polarity at the output terminals of the Cuk converter is its major disadvantage. Furthermore, the low-power conversion

Manuscript received July 27, 2019; revised November 15, 2019; accepted December 9, 2019. Date of publication December 16, 2019; date of current version February 28, 2020. Paper no. TII-19-3356.R1. (Corresponding author: Hasan Komurcugil.)

$\mathrm{H}$. Komurcugil is with the Department of Computer Engineering, Eastern Mediterranean University, Famagusta 99628, Turkey (e-mail: hasan. komurcugil@emu.edu.tr).

S. Biricik is with the Department of Electrical and Electronic Engineering, European University of Lefke, Lefke 99728, Turkey, and also with the School of Electrical and Electronic Engineering, Technological University Dublin, Dublin D08 X622, Ireland (e-mail: sbiricik@eul.edu.tr).

N. Guler is with the Department of Electrical and Energy, Technical Science Vocational School, Gazi University, Ankara 06560, Turkey (e-mail: nakiguler@gazi.edu.tr).

Color versions of one or more of the figures in this article are available online at http://ieeexplore.ieee.org.

Digital Object Identifier 10.1109/TII.2019.2960067 efficiency resulting from the hard switching condition can be considered as another drawback for the Cuk converter.

The SEPIC converter offers similar features as the Cuk converter without inverting the polarity of the output voltage. Moreover, the SEPIC converter provides great benefit for power conversion since it can generate a wide range of output noninverted voltage. The input impedance of a SEPIC converter can be changed by regulating the duty cycle. On the other hand, it is very suitable for either current or voltage applications as controlled current or voltage sources. This property makes the SEPIC converter an excellent candidate for PV applications because it can match the entire voltage and current characteristic curve [11], [12]. It can also be used in a variety of applications such as a power factor correction rectifier [13], voltage-doubler rectifier [14], PV charger [15], and motor drive [16]. However, the controller design for the SEPIC converter is very complicated due to its inherent fourth-order and nonlinear nature [17]. Furthermore, its behavior depends on operating conditions and load variations [11]. A well-designed controller should meet the desired objectives such as the fast dynamic response, robustness to parameter variations, guaranteed stability, and good tracking performance in case of input voltage and load variations. Various nonlinear control methods such as backstepping and passivity based control [18], fuzzy logic [19], and sliding mode control (SMC) [11], [20]-[22] have been proposed to achieve these objectives for the SEPIC converters.

Among these control methods, the SMC method merits attention owing to its excellent performance in satisfying the aforementioned control objectives. However, despite the prominent advantages of the existing SMC methods, they suffer from lack of controller design methodology and complexity. The sliding surface function formation of the SMC method presented in [20] is based on the linear combination of the input current error, output voltage error, and integral of these errors through suitable constants. Eventually, this method requires four constants and computation of the input current reference. However, there is no information about the criteria for selecting these constants and computing the input current reference. In [21], the sliding surface function formation is based on the linear combination of inductor current errors. Although no constant is required in this method, the computation of two different inductor current references is needed. The method presented in [22] is based on the error of the sum of inductor currents. However, there is no information about the computation of the desired current reference. Also, the SMC methods proposed in [20] and [21] are not verified experimentally. 


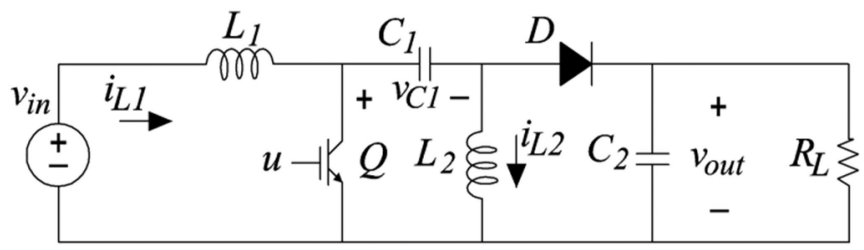

Fig. 1. Schematic diagram of the SEPIC converter.

In this article, an indirect SMC method is proposed for $\mathrm{dc}-\mathrm{dc}$ SEPIC converters. Unlike the existing SMC methods, the sliding surface function formation is based on the input current error only which requires no sliding constant. In such a case, the necessity of using sliding constants in the sliding surface function is eliminated. Also, it is shown that the output voltage control can be achieved indirectly. The existence conditions and existence region of the proposed SMC method are determined. The validity of the proposed SMC method is verified experimentally under buck and boost operation modes.

\section{MOdeling OF THE SEPIC CONVERTER}

Fig. 1 shows the schematic diagram of a SEPIC converter. The differential equations describing the operation of the SEPIC converter can be written as follows:

$$
\begin{aligned}
\frac{d i_{L_{1}}}{d t} & =\frac{v_{\text {in }}}{L_{1}}-(1-u) \frac{\left(v_{C_{1}}+v_{\text {out }}\right)}{L_{1}} \\
\frac{d i_{L_{2}}}{d t} & =\frac{v_{C_{1}}}{L_{2}} u-(1-u) \frac{v_{\text {out }}}{L_{2}} \\
\frac{d v_{C_{1}}}{d t} & =(1-u) \frac{i_{L_{1}}}{C_{1}}-\frac{i_{L_{2}}}{C_{1}} u \\
\frac{d v_{\text {out }}}{d t} & =(1-u) \frac{\left(i_{L_{1}}+i_{L_{2}}\right)}{C_{2}}-\frac{v_{\text {out }}}{C_{2} R_{L}}
\end{aligned}
$$

where $u$ is the control input which takes 1 for the ON state of the switch $Q$ and 0 for the OFF state. Clearly, the mathematical model of the converter has four differential equations that are dependent on each other.

\section{Variables in the Steady State}

The steady-state variables of the system corresponding to a constant value of the average control input $u$ can be obtained. Assuming that the output voltage and inductor current are equal to their references $\left(v_{\text {out }}=v_{\text {out }}^{*}\right.$ and $\left.i_{L_{1}}=i_{L_{1}}^{*}\right)$ and equating the derivatives of differential equations (1)-(4) to zero, the differential equations (1)-(4) can be written as

$$
\begin{aligned}
& 0=v_{\text {in }}-\left(1-u_{s s}\right)\left(v_{C_{1}}^{s s}+v_{\text {out }}^{*}\right) \\
& 0=u_{s s} v_{C_{1}}^{s s}-\left(1-u_{s s}\right) v_{\text {out }}^{*} \\
& 0=\left(1-u_{s s}\right) i_{L_{1}}^{*}-i_{L_{1}}^{s s} u_{s s} \\
& 0=\left(1-u_{s s}\right)\left(i_{L_{1}}^{*}+i_{L_{2}}^{s s}\right)-\frac{v_{\text {out }}^{*}}{R_{L}} .
\end{aligned}
$$

Solving for $u_{s s}, i_{L_{2}}^{s s}, i_{L_{1}}^{*}$, and $v_{C_{1}}^{s s}$ in terms of $v_{\text {out }}^{*}$ and $v_{\text {in }}$ yields

$$
\begin{aligned}
u_{s s} & =\frac{v_{\text {out }}^{*}}{v_{\text {in }}+v_{\text {out }}^{*}} \\
i_{L_{2}}^{s s} & =\frac{v_{\text {out }}^{*}}{R_{L}} \\
i_{L_{1}}^{*} & =\frac{\left(v_{\text {out }}^{*}\right)^{2}}{v_{\text {in }} R_{L}} \\
v_{C_{1}}^{s s} & =v_{\text {in }}
\end{aligned}
$$

where $u_{s s}, i_{L_{2}}^{s s}$, and $v_{C_{1}}^{s s}$ denote the steady-state values of $u, i_{L_{2}}$, and $v_{C_{1}}$, respectively. It is important to note that $u_{s s}$ is the duty cycle of the converter which should satisfy $0<u_{s s}<1$. From (9), the voltage transfer ratio can be deduced as

$$
\frac{v_{\mathrm{out}}^{*}}{v_{\mathrm{in}}}=\frac{u_{s s}}{1-u_{s s}} .
$$

Assuming that the converter operates in the continuous conduction mode, then $u_{s s}$ can take the following values in each operation mode:

$$
u_{s s} \begin{cases}<0.5 & \text { Buck mode } \\ =0.5 & \text { Neither Buck nor Boost mode } . \\ >0.5 & \text { Boost mode }\end{cases}
$$

Substituting the values presented in Table II $\left(v_{\text {in }}=30 \mathrm{~V}\right.$, $v_{\text {in }}=60 \mathrm{~V}$, and $v_{\text {out }}^{*}=48 \mathrm{~V}$ ) into (9), the values of $u_{s s}$ in the buck and boost modes are computed to be 0.44 and 0.61 , respectively.

By using the volt-second balance of $L_{1}$ in one switching period, one can obtain the expression for inductor current ripple as [15]

$$
\Delta i_{L 1}=2 i_{L 1, \min }=\frac{2 P_{\text {in }, \min }}{v_{\text {in }}}=\frac{v_{\text {in }}}{L_{1}} u_{s s, \max } T_{\mathrm{sw}}
$$

where $P_{\text {in,min }}$ and $T_{\mathrm{sw}}$ denote the minimum input power and switching period, respectively. Solving for $L_{1}$ yields

$$
L_{1}=\frac{v_{\text {in }}^{2} u_{s s, \max }}{2 P_{\mathrm{in}, \min } f_{\mathrm{sw}}} .
$$

It should be noted that the value of $L_{2}$ can be selected using (16). Using the values of $v_{\text {in }}, v_{\text {out }}$, and $f_{\text {sw }}$ presented in Table II, the value of $L_{1}$ is computed as $794.3 \mu \mathrm{H}$. However, in the experimental studies, both inductor values were selected as $800 \mu \mathrm{H}$.

On the other hand, the efficiency of the converter is given by

$$
\eta=\frac{P_{\text {out }}}{P_{\text {in }}}=\frac{P_{\text {out }}}{P_{\text {out }}+P_{\text {loss }}}
$$

where $P_{\text {loss }}$ denotes the total power loss in the converter due to switch, diode, and the resistance of inductors and capacitors. In [9], the equation of the power loss is presented. One can calculate that the power loss in the boost mode $\left(u_{s s}>0.5\right)$ is slightly less than that of the buck mode $\left(u_{s s}<0.5\right)$ for the same converter parameters. This means that the efficiency of the converter operating in the boost mode is slightly higher than that in the buck mode. 


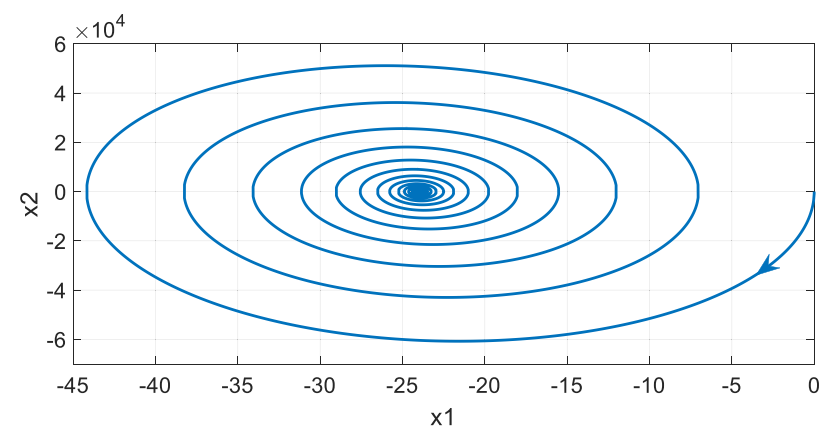

Fig. 2. State trajectory in phase plane for $u=0$.

\section{SLIDING MOdE CONTROL}

\section{A. Direct Voltage Control}

Let $x_{1}=v_{\text {out }}-v_{\text {out }}^{*}$ and $\dot{x}_{1}=x_{2}=\dot{v}_{\text {out }}$ be the state variables used to control $v_{\text {out }}$. The derivative of $x_{2}$ is given by

$$
\dot{x}_{2}=\ddot{v}_{\text {out }} .
$$

Substituting (4) into (18) yields

$$
\begin{aligned}
\dot{x}_{2}= & -\frac{x_{2}}{R_{L} C_{2}}+\frac{x_{1}(u-1)}{C_{2}}\left(\frac{L_{1}+L_{2}}{L_{1} L_{2}}\right) \\
& +\frac{(1-u)}{L_{1} C_{2}}\left(v_{\text {in }}-v_{C_{1}}-v_{\text {out }}^{*}\right) .
\end{aligned}
$$

The trajectories of the state variables can be observed by considering the ON $(u=1)$ and OFF $(u=0)$ states of the switch $Q$. Fig. 2 shows the trajectory in the phase plane for $u=0$ obtained with $L_{1}, L_{2}, C_{1}$, and $C_{2}$ presented in Table II (see Section V), $R_{L}=10 \Omega, v_{\text {in }}=30 \mathrm{~V}$, and $v_{\text {out }}^{*}=48 \mathrm{~V}$. The initial values of $x_{1}$ and $x_{2}$ are assumed to be zero.

In the steady state, since $x_{2}=0$ and $v_{C_{1}}=v_{\text {in }}$ (see Section III), then the solution of $x_{1}$ can be obtained from (19) as follows:

$$
x_{1}=-\frac{L_{2} v_{\text {out }}^{*}}{\left(L_{1}+L_{2}\right)} .
$$

It is evident from Fig. 2 that the trajectory exhibits a damped oscillation starting from initial point at $\left(x_{1}=0, x_{2}=0\right)$ and reaching to an equilibrium point at $\left(x_{1}=-24 \mathrm{~V}, x_{2}=0\right)$. The final value of $x_{1}\left(x_{1}=-v_{\text {out }}^{*} / 2=-24 \mathrm{~V}\right)$ is in agreement with (20) since $L_{1}=L_{2}$ in Table II. On the other hand, the state trajectory for $u=1$ does not exist as can be predicted from (19). In this case, it is not appropriate to select the sliding surface function as the linear combination of the state variables $x_{1}$ and $x_{2}$. Hence, it can be concluded that the closed-loop system with the direct voltage control is not stable.

\section{B. Indirect Voltage Control}

The output voltage is controlled indirectly by controlling the input current $i_{L_{1}}$. In order to achieve such control, the sliding surface function and its derivative are defined as follows:

$$
S=i_{L_{1}}-i_{L_{1}}^{*}, \frac{d S}{d t}=\frac{d i_{L_{1}}}{d t}-\frac{d i_{L_{1}}^{*}}{d t}
$$

where $i_{L_{1}}^{*}$ denotes the reference of $i_{L_{1}}$. Unlike the method presented in [23], the inductor current reference can be generated by using a proportional-integral (PI) controller without employing the compensation term as follows:

$$
i_{L_{1}}^{*}=-k_{p} x_{1}-k_{i} \int x_{1} d t
$$

where $k_{p}$ and $k_{i}$ are the proportional and integral gains, respectively. The derivative of (22) can be written as

$$
\frac{d i_{L 1}^{*}}{d t}=-k_{p} x_{2}-k_{i} x_{1} .
$$

Substituting (1) and (23) into the second equation in (21) gives

$$
\begin{aligned}
\frac{d S}{d t}= & \frac{1}{L_{1}}\left(L_{1} k_{i}+u-1\right) x_{1}+k_{p} x_{2} \\
& +\frac{1}{L_{1}}\left(v_{\text {in }}+v_{C_{1}}(u-1)+v_{\text {out }}^{*}(u-1)\right) .
\end{aligned}
$$

When the system enters into the sliding mode, its dynamics can be determined from $\frac{d S}{d t}=0$. In this case, the following equation can be written:

$$
\dot{x}_{1}+\left(\frac{L_{1} k_{i}-1+u}{L_{1} k_{p}}\right) x_{1}=\left(\frac{\left(v_{C_{1}}+v_{\text {out }}^{*}\right)(1-u)-v_{\text {in }}}{L_{1} k_{p}}\right) .
$$

Clearly, (25) is a first-order differential equation whose solution is given by

$$
x_{1}(t)=\left(\frac{\left(v_{C_{1}}+v_{\text {out }}^{*}\right)(1-u)-v_{\text {in }}}{L_{1} k_{i}+u-1}\right)+C e^{\frac{-\left(L_{1} k_{i}+u-1\right)}{L_{1} k_{p}} t} .
$$

Assuming that $x_{1}(0)=-v_{\text {out }}^{*}$, the constant $C$ in (26) can be obtained as

$$
C=\frac{u\left(v_{C_{1}}+v_{\mathrm{out}}^{*}\right)-\left(v_{C_{1}}+v_{\mathrm{out}}^{*}\right)+v_{\text {in }}}{L_{1} k_{i}+u-1}-v_{\text {out }}^{*} .
$$

It can be shown that the first term in (26) is zero in the steady state. In order to show this, $u$ should be replaced with its steadystate expression in (9) and $v_{C_{1}}$ should be replaced with $v_{\text {in }}$ in accordance with (12). On the other hand, the exponential term should converge to zero as $t \rightarrow \infty$. Hence, $x_{1}(t)$ tends to zero exponentially if the following condition is satisfied:

$$
\frac{\left(L_{1} k_{i}+u-1\right)}{L_{1} k_{p}}>0 .
$$

Since $(u-1)$ is always negative, the condition in (28) can be satisfied using $k_{p}$ and $k_{i}$ with appropriate signs such as $k_{p}>0$ and $k_{i}>0, k_{p}>0$ and $k_{i}<0, k_{p}<0$ and $k_{i}>0$, and $k_{p}<0$ and $k_{i}<0$.

Now, let the control input be defined as

$$
u=\frac{1}{2}(1-\operatorname{sign}(S))=\left\{\begin{array}{lll}
1 & \text { if } & S<0 \\
0 & \text { if } & S>0
\end{array}\right.
$$

where sign(.) denotes the sign function. The stability of the sliding mode is ensured if the following condition is satisfied [24]:

$$
S \frac{d S}{d t}<0
$$


Then, using (29) and (30), one can obtain the following existence conditions.

Case I:

When $S<0 \Rightarrow u=1$ and the condition for $\frac{d S}{d t}>0$ should be

$$
l_{1}=k_{i} x_{1}+k_{p} x_{2}+\frac{v_{\text {in }}}{L_{1}}>0
$$

Case II:

be

When $S>0 \Rightarrow u=0$ and the condition for $\frac{d S}{d t}<0$ should

$l_{2}=\frac{1}{L_{1}}\left(L_{1} k_{i}-1\right) x_{1}+k_{p} x_{2}+\frac{1}{L_{1}}\left(v_{\text {in }}-v_{C_{1}}-v_{\text {out }}^{*}\right)<0$.

Equations (31) and (32) denote two straight lines which constitute the borders of the stability region of the system. The slopes of these lines are given by

$$
\text { Slope }_{l_{1}}=1-k_{i} \text { and Slope } l_{2}=-\frac{k_{i}}{k_{p}} .
$$

It is obvious from (33) that the slope of $l_{1}$ depends only on $k_{i}$. However, the slope of $l_{2}$ depends on both $k_{p}$ and $k_{i}$. The signs of $k_{p}$ and $k_{i}$ can change the slopes of these lines and, hence, the stability region accordingly. Therefore, considering the condition in (28) and the slopes in (33), there exist four different stability regions for each $k_{p}$ and $k_{i}$ pair, as shown in Fig. 3. Close inspection to the stability regions shows that the inductor $L_{1}$ plays significant role in determining the size of the region. Although increasing $L_{1}$ decreases the ripple component of $i_{L 1}$, the size of the stability region is also decreased. Hence, $L_{1}$ should be selected to make a compromise between the ripple of $i_{L 1}$ and stability region.

On the other hand, the necessary condition for the existence of a sliding motion on the sliding surface can also be verified if the transversality, reachability, and equivalent control conditions are satisfied [25]. The transversality condition as follows constitutes the necessary condition for the existence of a sliding motion on the sliding surface:

$$
\frac{\partial}{\partial u}\left(\frac{d S}{d t}\right) \neq 0
$$

Equation (34) guarantees that the control input $u$ is present in $d S / d t$, which is needed to govern the sliding mode dynamics of the system.

The transversality condition can easily be verified by substituting (24) into (34) which yields

$$
\frac{\partial}{\partial u}\left(\frac{d S}{d t}\right)=\frac{v_{C_{1}}+v_{\text {out }}}{L_{1}} \neq 0 .
$$

Clearly, the transversality condition is satisfied since $v_{C_{1}}$, $v_{\text {out }}$, and $L_{1}$ are all positive.

The expression for the equivalent control input can be obtained by imposing $\frac{d S}{d t}=0$ and $u=u_{\mathrm{eq}}$ in (24) and solving for $u_{\text {eq }}$ results in

$$
u_{\mathrm{eq}}=\frac{v_{C_{1}}+v_{\mathrm{out}}-v_{\mathrm{in}}}{v_{C_{1}}+v_{\mathrm{out}}} .
$$

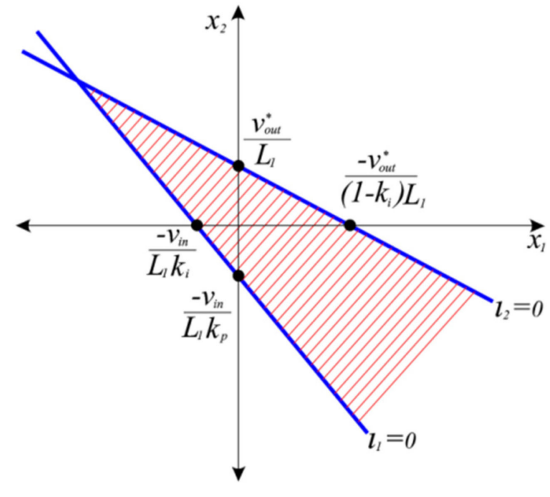

(a)

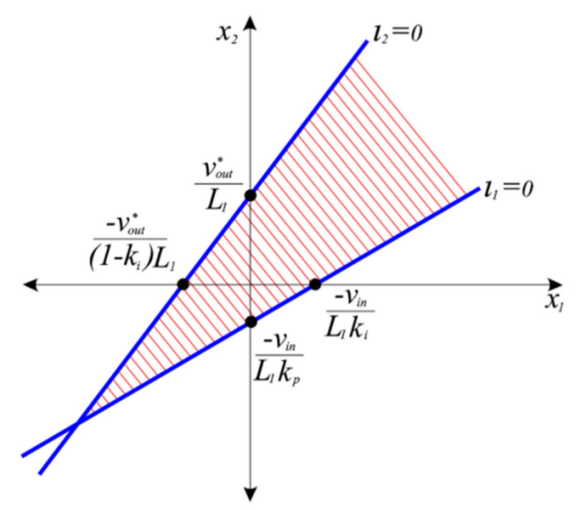

(b)

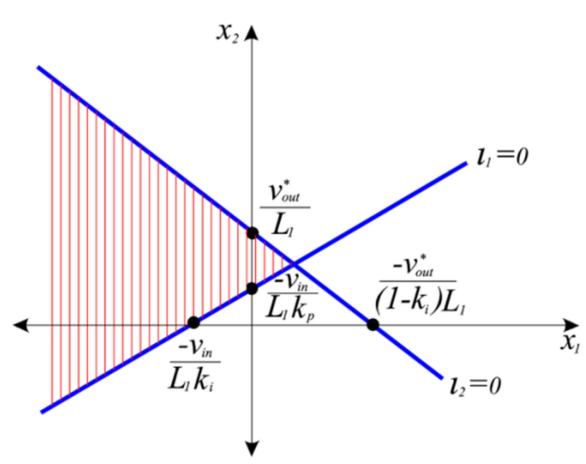

(c)

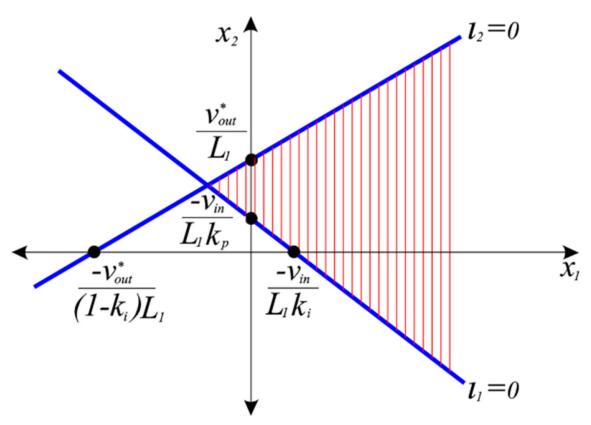

(d)

Fig. 3. Stability regions of the system with the proposed SMC method. (a) $k_{p}>0$ and $k_{i}>0$. (b) $k_{p}>0$ and $k_{i}<0$. (c) $k_{p}<0$ and $k_{i}>0$. (d) $k_{p}<0$ and $k_{i}<0$. 
It is worth noting that $u_{\text {eq }}$ is a continuous signal which should be constrained between the maximum and minimum values of the discontinuous control input $u$. In the case of dc-dc converters, $u_{\text {eq }}$ is constrained between 1 and 0 . Now, let us show that $0<u_{\mathrm{eq}}<1$. Using (1) and (21), the condition in (30) can be expressed as

$$
\frac{1}{L_{1}} S\left[\left(v_{\text {in }}-v_{C_{1}}-v_{\text {out }}\right)+\left(v_{C_{1}}+v_{\text {out }}\right) u-\frac{d i_{L 1}^{*}}{d t}\right]<0 .
$$

Substituting (29) into (37) and by making use of $S=$ $|S| \operatorname{sign}(S)$, one can obtain

$$
\begin{gathered}
\frac{1}{2 L_{1}}|S|\left\{\operatorname{sign}(S)\left[\left(2 v_{\text {in }}-v_{C_{1}}-v_{\text {out }}\right)-2 L_{1} \frac{d i_{L 1}^{*}}{d t}\right]\right. \\
\left.-\left(v_{C_{1}}+v_{\text {out }}\right)\right\}<0 .
\end{gathered}
$$

The inequality in (38) holds if the following condition is satisfied:

$$
\left|\left(2 v_{\text {in }}-v_{C_{1}}-v_{\text {out }}\right)-2 L_{1} \frac{d i_{L 1}^{*}}{d t}\right|<\left(v_{C_{1}}+v_{\text {out }}\right) .
$$

In the steady state, $\frac{d i_{L 1}^{*}}{d t}=0$ since $i_{L 1}^{*}$ is constant. Hence, (39) can be written as

$$
-\left(v_{C_{1}}+v_{\text {out }}\right)<\left(2 v_{\text {in }}-v_{C_{1}}-v_{\text {out }}\right)<\left(v_{C_{1}}+v_{\text {out }}\right) .
$$

Now, adding $\left(v_{C_{1}}+v_{\text {out }}\right)$ to inequality (40) and dividing all terms of the resulting equation by 2 yields

$$
0<v_{\text {in }}<\left(v_{C_{1}}+v_{\text {out }}\right) .
$$

Multiplying (41) by -1 and then adding $\left(v_{C_{1}}+v_{\text {out }}\right)$ to the resulting equation yields

$$
0<\left(v_{C_{1}}+v_{\text {out }}-v_{\text {in }}\right)<\left(v_{C_{1}}+v_{\text {out }}\right) .
$$

Now, dividing all terms of (42) by $\left(v_{C_{1}}+v_{\text {out }}\right)$, we obtain

$$
0<\underbrace{\left(\frac{v_{C_{1}}+v_{\text {out }}-v_{\text {in }}}{v_{C_{1}}+v_{\text {out }}}\right)}_{u_{\text {eq }}}<1 .
$$

Since $v_{C_{1}}=v_{\text {in }}$ and $v_{\text {out }}=v_{\text {out }}^{*}$ are in the steady state, $u_{\text {eq }}$ reduces to $u_{s s}$ given in (9).

It is important to note that the direct implementation of (29) gives rise to high switching frequency and chattering which are not desired in practice. As a remedy to this problem, the sliding surface function is forced to move between the upper and lower thresholds known as the hysteresis bands as follows:

$$
u=\frac{1}{2}(1-\operatorname{sign}(S))=\left\{\begin{array}{ll}
1 & \text { if } S<-h \\
0 & \text { if } S>+h
\end{array} .\right.
$$

Block diagram of the proposed control strategy with the SEPIC converter is depicted in Fig. 4.

The existing sliding mode controlled topologies (with buckboost ability) similar to the SEPIC converter are compared with the proposed SMC. The comparison is in terms of the state variables and constants in the sliding surface function. For the sake of implementation cost, the required number of sensors is

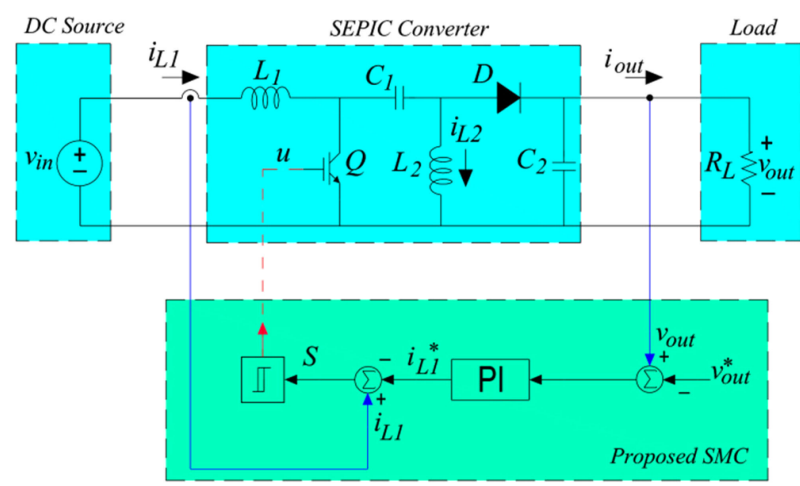

Fig. 4. Block diagram of the proposed controller with the SEPIC converter.

TABLE I

COMPARISON OF THE EXISTING TOPOLOGIES WITH PROPOSED SMC

\begin{tabular}{|l|l|c|c|}
\hline Topology & Type of S & $\begin{array}{l}\text { No. of state variables } \\
\text { and constants in S } \\
\text { and no. of required } \\
\text { sensors }\end{array}$ & References \\
\hline Cuk & $\begin{array}{l}\text { Linear combin. of } \\
\text { state variables }\end{array}$ & $\begin{array}{l}4,4,5 \text { sensors for [3] } \\
4,4,5 \text { sensors for [4] }\end{array}$ & {$[3],[4]$} \\
\hline Buck-Boost & $\begin{array}{l}\text { Linear combin. of } \\
\text { state variables }\end{array}$ & $\begin{array}{l}3,3,1 \text { sensor for [26] } \\
3,3,2 \text { sensors for [27] }\end{array}$ & {$[26],[27]$} \\
\hline Sepic & Linear combin. of & $2,2,2$ sensors & {$[11]$} \\
\cline { 2 - 4 } & state variables & $3,3,2$ sensors & {$[20]$} \\
\cline { 2 - 4 } & $\begin{array}{l}\text { Linear combin. of } \\
\text { inductor currents }\end{array}$ & $2,0,2$ sensors & {$[21]$} \\
\cline { 2 - 4 } & $\begin{array}{l}\text { Inductor current } \\
\text { error }\end{array}$ & $1,0,2$ sensors & Proposed \\
\hline
\end{tabular}

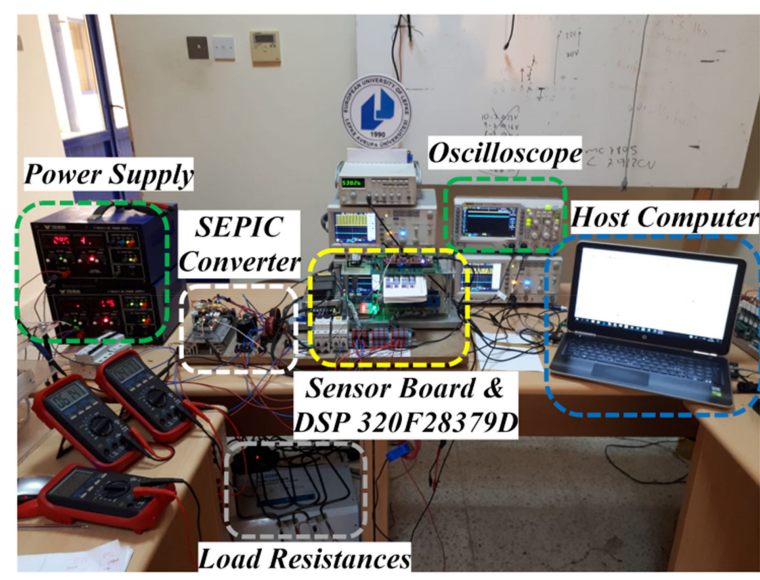

Fig. 5. Experimental setup.

considered as well. According to Table I, the proposed SMC is based on the simplest sliding surface function with no constant leading to reduced implementation complexity.

\section{Simulation AND EXPERIMENTAL RESULtS}

The theoretical considerations are verified by simulations and experimentally. The experimental results are obtained using the setup shown in Fig. 5. The input and output voltages are 
TABLE II

System AND CONTROL PARAMETERS

\begin{tabular}{|l|l|}
\hline \multicolumn{1}{|c|}{ Description and Symbol } & Value \\
\hline Input voltage: $v_{i n}$ & $30 \mathrm{~V}$ and $60 \mathrm{~V}$ \\
\hline Capacitors: $C_{1}, C_{2}$ & $330 \mu \mathrm{F}$ \\
\hline Inductors: $L_{1}, L_{2}$ & $800 \mu \mathrm{H}$ \\
\hline Reference output voltage: $v_{\text {out }}^{*}$ & $48 \mathrm{~V}$ \\
\hline Proportional and integral gains: $k_{p}$ and $k_{i}$ & 0.25 and 10 \\
\hline Hysteresis band: $h$ & $+0.12 /-0.12$ \\
\hline Sampling time: $T_{s}$ & $10 \mu \mathrm{s}$ \\
\hline Switching frequency: $f_{s}$ & $15 \mathrm{kHz}$ \\
\hline Load $1, R_{L 1}$ & $100 \Omega$ \\
\hline Load $2, R_{L 2}$ & $50 \Omega$ \\
\hline
\end{tabular}

measured by using LEM LV25-P. The input and output currents are measured by using LEM LA55-P current transducer. The proposed SMC strategy modeled in Simulink and embedded into TMS320F28379D by using the MATLAB/Simulink and code composer studio software. The performance of the proposed control method is tested in terms of voltage regulation ability under variable input voltage and different load conditions. The system and control parameters used in the experimental studies are given in Table II.

\section{A. Steady-State Performance}

Fig. 6 shows the steady-state results of input voltage $\left(v_{\text {in }}\right)$, output voltage $\left(v_{\text {out }}\right)$, and inductor currents $\left(i_{L 1}\right.$ and $\left.i_{L 2}\right)$ under $R_{L}=100 \Omega$ in the buck and boost modes. It is clear from Fig. 6 that the output voltage is $48 \mathrm{~V}$ which means that the controller regulates the output voltage at its reference. In addition, the converter with the proposed control method successfully operates both in buck and in boost modes, as shown in Fig. 6(a) and (b), respectively.

\section{B. Performance Under Input Voltage Variations}

Fig. 7 shows the dynamic responses of $v_{\text {out }}, i_{L 1}$, and $i_{\text {out }}$ currents for an abrupt change in $v_{\text {in }}$ under $v_{\text {out }}^{*}=48 \mathrm{~V}$ and $R_{L_{1}}=100 \Omega$. The results presented in Fig. 7(a) and (b) correspond to the input voltage variation from 60 to $30 \mathrm{~V}$ and from 30 to $60 \mathrm{~V}$. It is worth noting that, initially, the converter operates in the buck mode for $v_{\text {in }}=60 \mathrm{~V}$. However, when the input voltage is changed from 60 to $30 \mathrm{~V}$, the operation mode of the converter is changed from buck mode to boost mode. Similarly, when the input voltage is changed from 30 to $60 \mathrm{~V}$, the converter's operation is changed from boost mode to buck mode. In these operating mode changes, the input current is also changed accordingly so that the power delivered to the load is unchanged. It can be noticed that the output voltage tracks its reference successfully and regulated at $48 \mathrm{~V}$ in both operating modes. In Fig. 8(b), there exist small undesired ripples on the

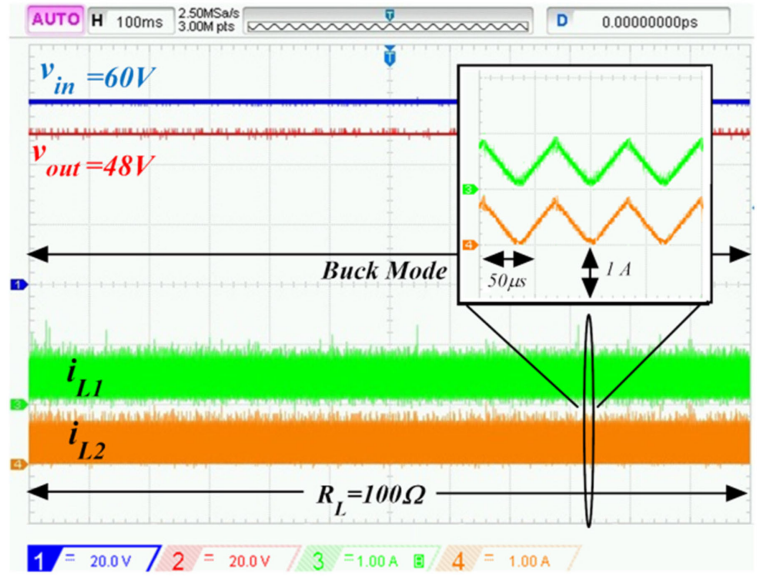

(a)

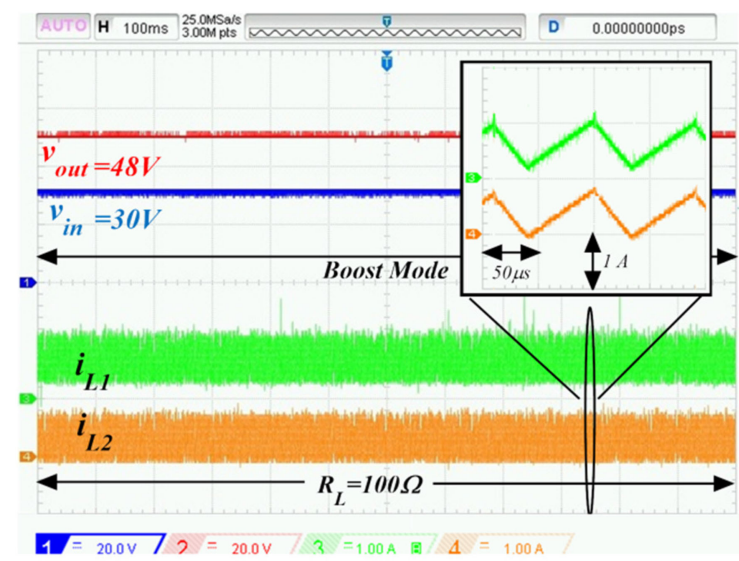

(b)

Fig. 6. Experimental steady-state responses of the input voltage, output voltage, and inductor currents under $R_{L}=100 \Omega$ in (a) buck mode and (b) boost mode.

output current which occur due to the noise disturbance in the experimental system [29].

The results presented in Fig. 7(c) and (d) correspond to the input voltage variation from 30 to $60 \mathrm{~V}$ and back to $30 \mathrm{~V}$. Initially, the converter operates in the boost mode for $v_{\text {in }}=30 \mathrm{~V}$. When the input voltage is changed from 30 to $60 \mathrm{~V}$, the converter's operation is changed to buck mode. When the input voltage is changed from 60 to $30 \mathrm{~V}$, the converter's operation is changed to boost mode again. Clearly, the output voltage is regulated at $48 \mathrm{~V}$ in both operating modes. Again, in order to maintain the load power against this input voltage variations, the input power should also be changed which is possible if the input current is changed.

\section{Performance Under Load Variations}

The performance of the proposed control strategy is also tested under $100 \%$ load variations. Fig. 8 shows the dynamic responses of output voltage, and input and output currents for an abrupt change in the load resistance when $v_{\text {out }}^{*}=48 \mathrm{~V}$. The load change was from 100 to $50 \Omega$ and from 50 to $100 \Omega$. Fig. 8(a) and (b) shows the dynamic responses due to these load changes when 

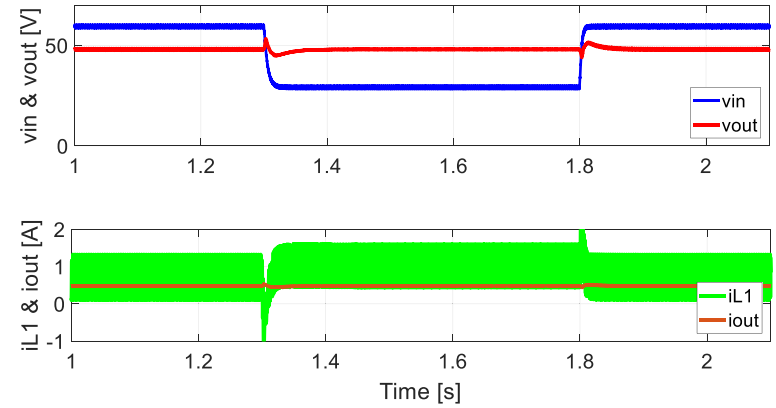

(a)
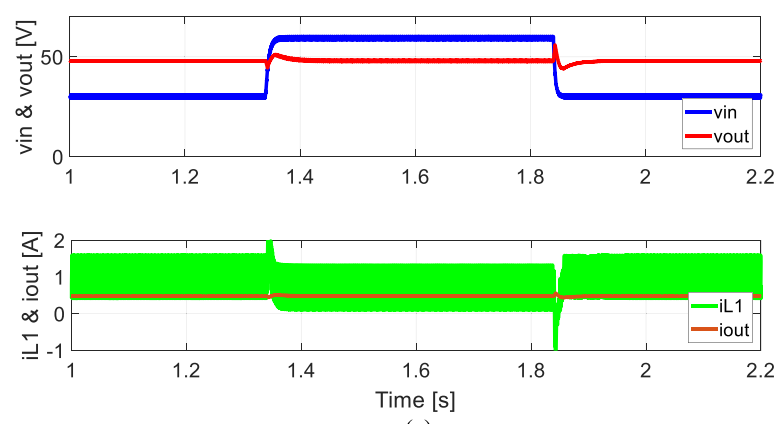

(c)

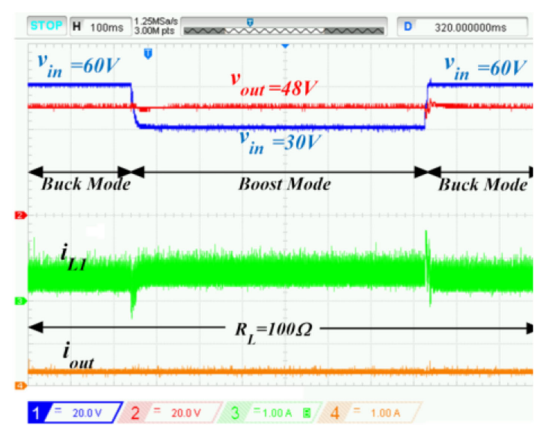

(b)

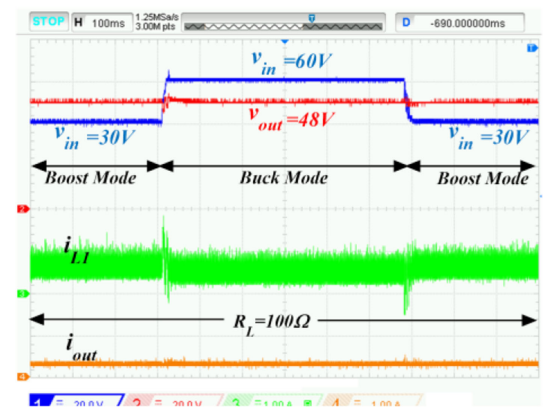

(d)

Fig. 7. Simulated and experimental dynamic responses of the output voltage, and input and output currents for the abrupt change in the input voltage. (a) and (b) From 60 to $30 \mathrm{~V}$ and from 30 to $60 \mathrm{~V}$. (c) and (d) From 30 to $60 \mathrm{~V}$ and from 60 to $30 \mathrm{~V}$.

TABLE III

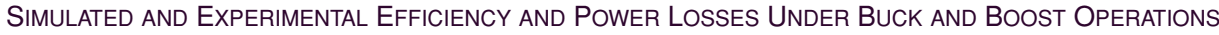

\begin{tabular}{|c|c|c|c|c|c|c|c|c|c|c|}
\hline \multirow{2}{*}{\multicolumn{2}{|c|}{ Operation Mode }} & \multirow{3}{*}{$\begin{array}{r}R_{L}(\Omega) \\
\\
\\
100\end{array}$} & \multicolumn{2}{|c|}{$P_{\text {in }}(W)$} & \multicolumn{2}{|c|}{$\mathrm{P}_{\text {out }}(\mathrm{W})$} & \multicolumn{2}{|c|}{ Losses (W) } & \multicolumn{2}{|c|}{ Efficiency, $\eta(\%)$} \\
\hline & & & \multirow{2}{*}{$\frac{\text { Simulation }}{28.35}$} & \multirow{2}{*}{$\begin{array}{l}\text { Exp. } \\
28.5\end{array}$} & \multirow{2}{*}{$\frac{\text { Simulation }}{24}$} & \multirow{2}{*}{$\begin{array}{c}\text { Exp. } \\
23.63\end{array}$} & \multirow{2}{*}{\begin{tabular}{|c} 
Simulation \\
4.35
\end{tabular}} & \multirow{2}{*}{$\begin{array}{l}\text { Exp. } \\
4.87\end{array}$} & \multirow{2}{*}{$\frac{\text { Simulation }}{84.66}$} & \multirow{2}{*}{$\begin{array}{r}\text { Exp. } \\
82.91\end{array}$} \\
\hline & & & & & & & & & & \\
\hline & & 50 & 54.9 & 55.2 & 47.8 & 48 & 7.1 & 7.2 & 87.07 & $86, .96$ \\
\hline & & 33.33 & 77.06 & 77.45 & 69.5 & 70 & 7.56 & 7.45 & 90.19 & 90.38 \\
\hline \multirow[t]{4}{*}{ Buck } & \multirow{4}{*}{$\begin{array}{l}\mathrm{v}_{\text {in }}=60 \mathrm{~V} \\
\mathrm{v}_{\text {out }}=48 \mathrm{~V}\end{array}$} & 25 & 100 & 101 & 93 & 93.5 & 7 & 7.5 & 93.00 & 92.57 \\
\hline & & 16 & 154 & 155 & 144 & 144 & 10 & 11 & 93.51 & 92.90 \\
\hline & & 10 & 248 & 250 & 229 & 230.5 & 19 & 19.5 & 92.34 & 92.20 \\
\hline & & 8 & 313.5 & 315 & 286 & 288 & 27.5 & 27 & 91.23 & 91.43 \\
\hline \multirow[b]{7}{*}{ Boost } & \multirow{7}{*}{$\begin{array}{l}V_{\text {in }}=30 \mathrm{~V} \\
v_{\text {out }}=48 \mathrm{~V}\end{array}$} & 100 & 26 & 26.5 & 22.5 & 23 & 3.5 & 3.5 & 86.54 & 86.79 \\
\hline & & 50 & 51 & 52 & 46.2 & 46.5 & 4.8 & 5.5 & 90.59 & 89.42 \\
\hline & & 33.33 & 75 & 75.5 & 69.6 & 70 & 5.4 & 5.5 & 92.80 & 92.72 \\
\hline & & 25 & 97.5 & 98 & 93 & 93.5 & 4.5 & 4.5 & 95.38 & 95.41 \\
\hline & & 16 & 150.2 & 151 & 143 & 144 & 7.2 & 7 & 95.21 & 95.36 \\
\hline & & 10 & 243 & 245 & 229.8 & 231 & 13.2 & 14 & 94.57 & 94.29 \\
\hline & & 8 & 308.5 & 310 & 286 & 288 & 22.5 & 22 & 92.71 & 92.90 \\
\hline
\end{tabular}

the converter operates in the buck mode. As can be seen clearly, the output voltage is almost not affected from these load changes. This means that the proposed controller is able to regulate the output voltage under load variations.

Fig. 8(c) and (d) shows the dynamic responses due these load changes when the converter operates in the boost mode. Again, it can be seen that except for the small overshoot and undershoot occurring during the transition period, the output voltage is not affected from the load changes.

Fig. 9 shows the experimental dynamic responses of output voltage, and input and output currents obtained with the SMC method presented in [10] for an abrupt change in the input 

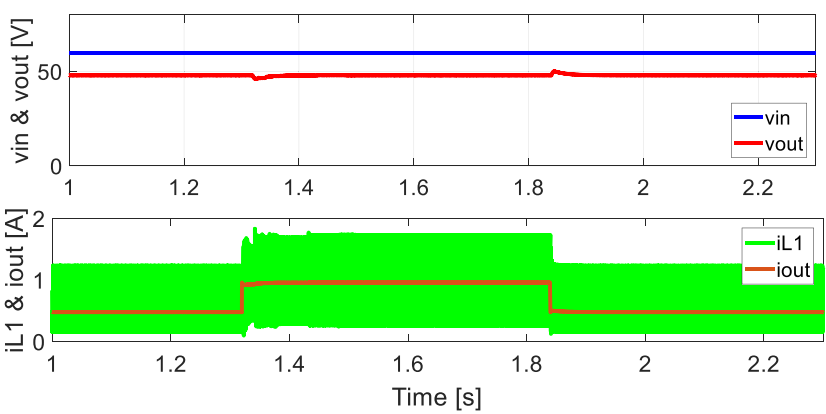

(a)

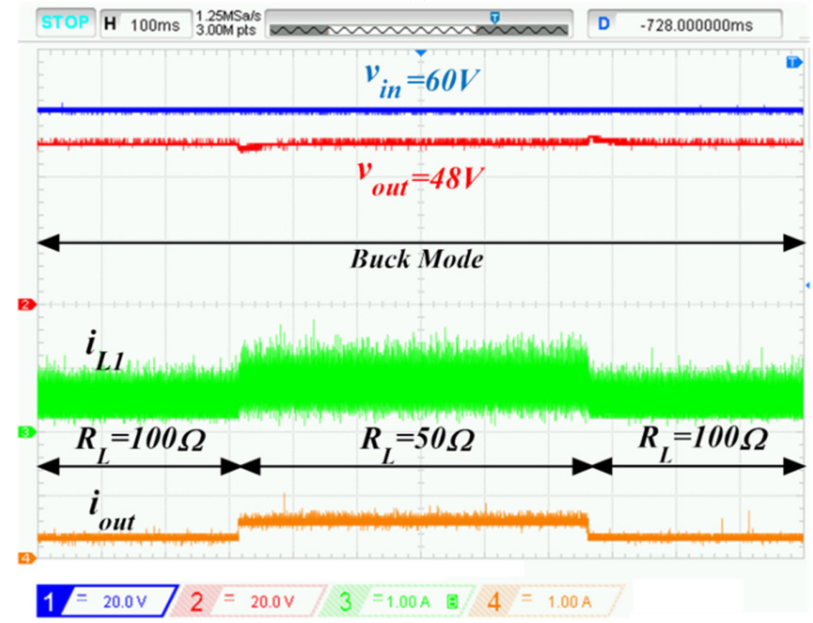

(b)
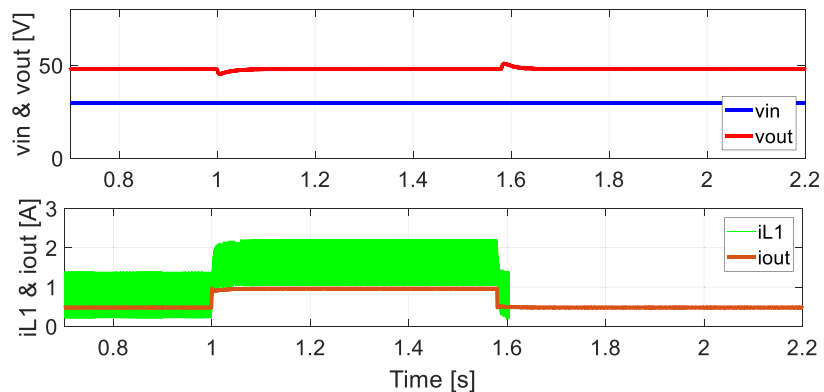

(c)

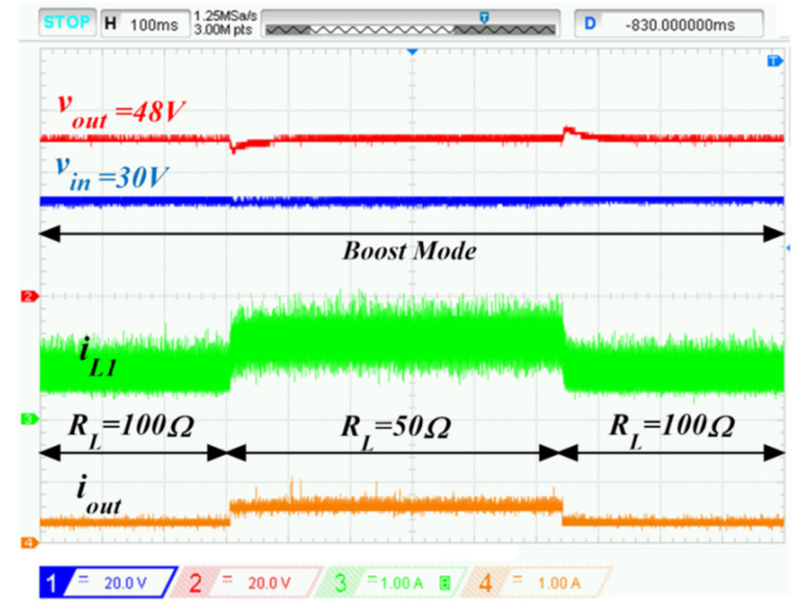

(d)

Fig. 8. Simulated and experimental dynamic responses during load change from 100 to $50 \Omega$ and back to $100 \Omega$. (a) and (b) Buck mode. (c) and (d) Boost mode.

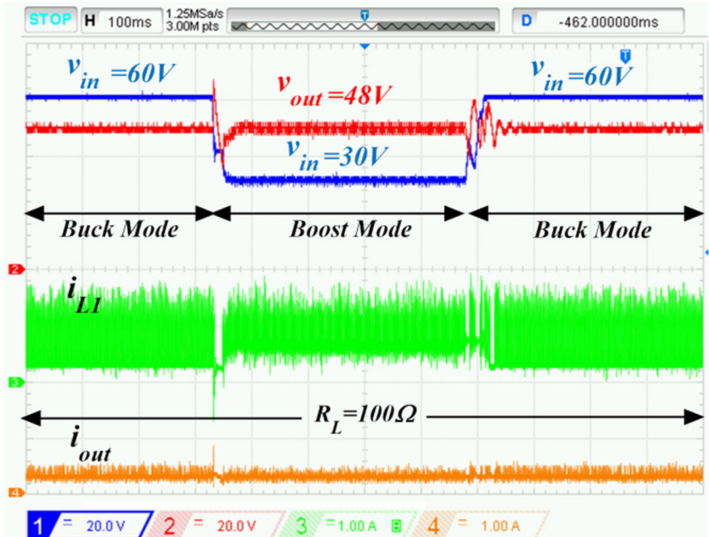

Fig. 9. Experimental dynamic responses of the output voltage, and input and output currents for the abrupt change in the input voltage from 60 to $30 \mathrm{~V}$ and from 30 to $60 \mathrm{~V}$ using control method in [10]

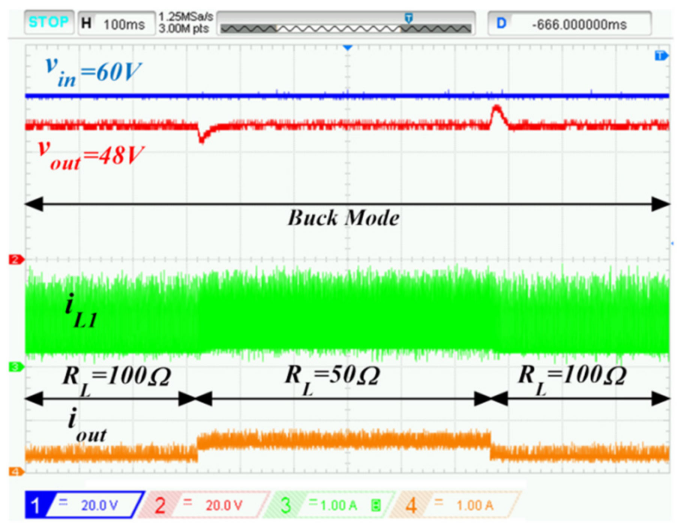

(a)

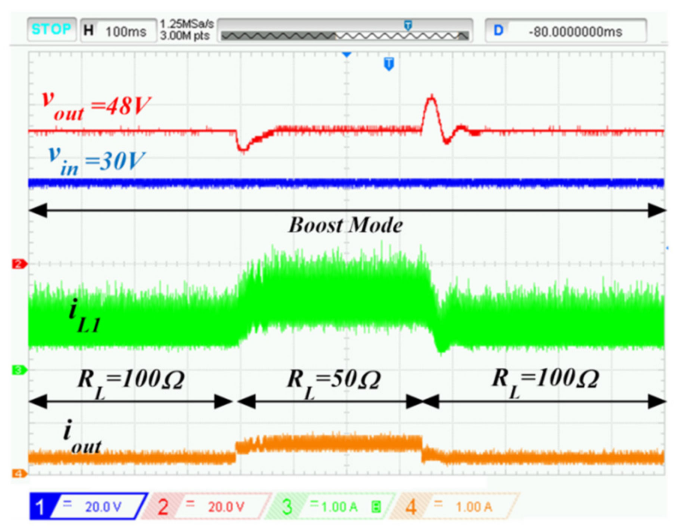

(b)

Fig. 10. Experimental dynamic responses during load change from 100 to $50 \Omega$ and back to $100 \Omega$ obtained by the control method presented in [10]. (a) Buck mode. (b) Boost mode.

voltage when $v_{\text {out }}^{*}=48 \mathrm{~V}$ and $R_{L_{1}}=100 \Omega$. Comparing Fig. 9 with Fig. 7(b), one can see that the proposed control is much faster. As can be seen from Fig. 9, there are some oscillations in the output voltage that occur during the transient of input 


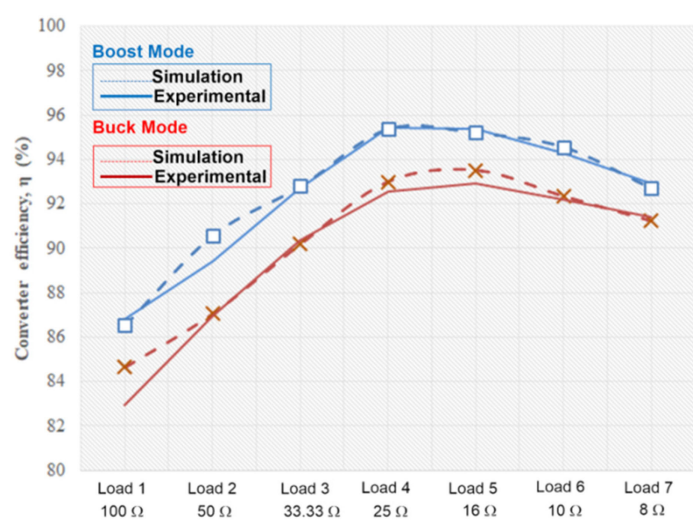

(a)

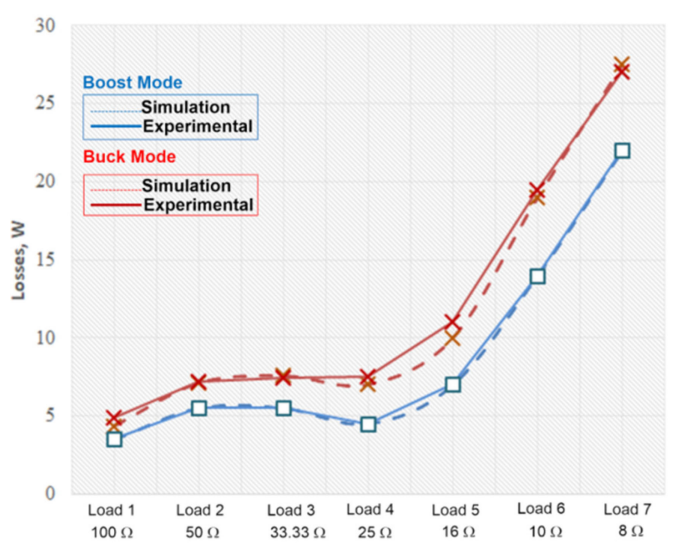

(b)

Fig. 11. Simulated and measured efficiency and power losses of the SEPIC converter with the proposed controller under buck and boost operation. (a) Efficiency. (b) Power losses.

voltage change from 60 to $30 \mathrm{~V}$. Such undesired oscillations do not occur in the output voltage obtained by the proposed control method as shown Fig. 7(b). This means that the proposed control is much faster than the control presented in [10].

Fig. 10 shows the experimental dynamic responses of output voltage, and input and output currents obtained with the SMC method presented in [10] for an abrupt change in the load resistance when $v_{\text {out }}^{*}=48 \mathrm{~V}$. The load change was from 100 to $50 \Omega$ and from 50 to $100 \Omega$. Although the controller regulates the output voltage at the desired level $(48 \mathrm{~V})$, its dynamic response is slow. This fact is evident when Fig. 10 is compared with Fig. 8. The undershoot and overshoot in the output voltage in Fig. 10 are discernible.

\section{Efficiency Analysis}

The main power losses in the converter are due to the switching losses, diode losses, inductor losses, and snubber circuit losses. The efficiency of converter $(\eta)$ becomes maximum if these power losses are minimized. In order to investigate the efficiency of the converter, the input and output powers are simulated and measured in boost and buck modes under seven different resistive loads. Then, the power losses and efficiency are computed. The results are tabulated in Table III and plotted in Fig. 11.
In the buck mode operation, the maximum efficiency can be achieved at load $5(16 \Omega)$. The simulated and experimental efficiency values at this load are $93.51 \%$ and $92.9 \%$, respectively. In the boost mode, the maximum efficiency exists at load 4 $(25 \Omega)$. The simulated and experimental efficiency values at 25 $\Omega$ are $95.38 \%$ and $95.41 \%$, respectively. It is clear from Table III that the simulated power, losses, and efficiency values are in good agreement with their counterpart obtained experimentally. Also, it is worth noting that the boost mode has slightly higher efficiency than the efficiency attained in the buck mode operation.

\section{CONCLUSION}

In this article, an indirect SMC with simplified sliding surface function was proposed for dc-dc SEPIC converters. It was shown that the output voltage control could be achieved indirectly by using the sliding surface function based on the input current error. The use of such a sliding surface function not only simplified the design but also reduced the implementation cost. The existence region of the sliding mode was determined for various PI gains. The input current reference was generated via a PI regulator. The performance of the proposed SMC method was tested on a laboratory prototype converter, operated in the buck and boost modes, in terms of the voltage regulation ability under abrupt changes in the input voltage and load resistance. The theoretical considerations were validated by the experimental results. These results showed that the proposed SMC method offers advantages in terms of reduced implementation complexity and cost.

\section{REFERENCES}

[1] M. Rashid, Power Electronics: Circuits, Devices, and Applications, 4th ed. London, U.K.: Pearson, 2013.

[2] B. Poorali, E. Adib, and H. Farzanehfard, "Soft-switching DC-DC Cuk converter operating in discontinuous-capacitor-voltage mode," IET Power Electron., vol. 10, no. 13, pp. 1679-1686, 2017.

[3] L. Malesani, L. Rossetto, G. Spiazzi, and P. Tenti, "Performance optimization of Cuk converters by sliding-mode control," IEEE Trans. Power Electron., vol. 10, no. 3, pp. 302-309, May 1995.

[4] S. C. Tan and Y. M. Lai, "Constant-frequency reduced-state sliding mode current controller for Cuk converters," IET Power Electron., vol. 1, no. 4, pp. 466-477, 2008.

[5] M. A. Al-Saffar, E. H. Ismail, A. J. Sabzali, and A. A. Fardoun, "An improved topology of SEPIC converter with reduced output voltage ripple," IEEE Trans. Power Electron., vol. 23, no. 5, pp. 2377-2386, May 2008.

[6] L. K. Wong and T. K. Man, "Small signal modelling of open-loop SEPIC converters," IET Power Electron., vol. 3, no. 6, pp. 858-868, 2010.

[7] A. Cantillo, A. D. Nardo, N. Femia, and W. Zamboni, "Stability issues in peak-current-controlled SEPIC," IEEE Trans. Power Electron., vol. 26 , no. 2, pp. 551-562, Feb. 2011.

[8] E. Babaei, and M. E. S. Mahmoodieh, "Calculation of output voltage ripple and design considerations of SEPIC converter," IEEE Trans. Ind. Electron., vol. 61, no. 3, pp. 1213-1222, Mar. 2014.

[9] E. Babaei and M.E. S. Mahmoodieh, "Analysis and investigation of energy transmission process in different operating modes of SEPIC converter," IET Power Electron., vol. 7, no. 4, pp. 819-828, 2014.

[10] H. Zhang, C. Yi, and T. Wei, "Non-linear modal analysis of transient interaction behaviours in SEPIC DC-DC converters," IET Power Electron., vol. 10, no. 10, pp. 1190-1199, Oct. 2017.

[11] E. Mamarelis, G. Petrone, and G. Spagnuolo, "Design of a sliding-modecontrolled SEPIC for PV MPPT applications," IEEE Trans. Ind. Electron., vol. 61, no. 7, pp. 3387-3398, Jul. 2014. 
[12] M. Killi and S. Samantha, "An adaptive voltage-sensor-based MPPT for photovoltaic systems with SEPIC converter including steady-state and drift analysis," IEEE Trans. Ind. Electron., vol. 62, no. 12, pp. 7609-7619, Dec. 2015.

[13] Y. Liu, Y. Sun, and M. Su, "A control method for bridgeless Cuk/Sepic PFC rectifier to achieve power decoupling," IEEE Trans. Ind. Electron. vol. 64, no. 9, pp. 7272-7276, Sep. 2017

[14] P. J. S. Costa, C. H. I. Font, and T. B. Lazzarin, "A family of single-phase voltage-doubler high-power-factor SEPIC rectifiers operating in DCM,' IEEE Trans. Power Electron., vol. 32, no. 6, pp. 4279-4290, Jun. 2017.

[15] S. J. Chiang, H. J. Shieh, and M. C. Chen, "Modeling and control of PV charger system with SEPIC converter," IEEE Trans. Ind. Electron., vol. 56 , no. 11, pp. 4344-4353, Nov. 2009.

[16] R. Kumar, and B. Singh, "Solar PV array fed water pumping system using SEPIC converter based BLDC motor drive," in Proc. 18th Nat. Power Syst. Conf., 2014, pp. 1-5.

[17] K. M. Tsang and W. L. Chan, "Fast acting regenerative DC electronic load based on a SEPIC converter," IEEE Trans. Power Electron., vol. 27, no. 1, pp. 269-275, Jan. 2012.

[18] S. Biricik, T. Ngo, H. Komurcugil, and M. Basu, "Nonlinear control methods for single-ended primary-inductor power converters," in Proc. 43nd Annu. Conf. IEEE Ind. Electron. Soc., Beijing, China, Oct. 29/Nov. 1, 2017.

[19] A. E. Khateb, N. A. Rahim, J. Selvaraj, and N. Uddin, "Fuzzy-logiccontroller-based SEPIC converter for maximum power point tracking,' IEEE Trans. Ind. Appl., vol. 50, no. 4, pp. 2349-2358, Jul./Aug. 2014.

[20] G. Gireesh, and P. N. Seema, "High frequency SEPIC converter with PWM integral sliding mode control," in Proc. IEEE Int. Conf. Technol. Advancements Power Energy, 2015, pp. 393-397.

[21] J. E. S. Duque, E. I. O. Rivera, and J. G. Llorente, "Analysis and nonlinear control of SEPIC dc-dc converter in photovoltaic systems," in Proc. IEEE Workshop Power Electron. Power Qual. Appl., 2015, pp. 1-6.

[22] A. Kavitha, G. Indira, and G. Uma, "Analysis and control of chaos in SEPIC dc-dc converter using sliding mode control," in Proc. IEEE Industry Appl. Soc. Annu. Meeting, 2008, pp. 1-6.

[23] Z. Chen, W. Gao, J. Hu, and X. Ye, "Closed-loop analysis and cascade control of a nonminimum phase boost converter," IEEE Trans. Power Electron., vol. 26, no. 4, pp. 1237-1252, Apr. 2011.

[24] J.-J. E. Slotine and W. Li, Applied Nonlinear Control. Englewood Cliffs, NJ, USA: Prentice-Hall, 1991

25] D. G. Montoya, C. A. Ramos-Paja, and R. Giral, "Improved design of sliding mode controllers based on the requirements of MPPT techniques," IEEE Trans. Power Electron., vol. 31, no. 1, pp. 235-247, Jan. 2016.

[26] S. C. Tan, Y. M. Lai, and C. K. Tse, "A unified approach to the design of PWM-based sliding-mode voltage controllers for basic DC-DC converters in continuous conduction mode," IEEE Trans. Circuit Syst.-I, vol. 53, no. 8 pp. 1816-1827, Aug. 2006.

[27] M. Salimi, J. Soltani, A. Zakipour, and N. R. Abjadi, "Hyper-plane sliding mode control of the DC-DC buck/boost converter in continuous and discontinuous conduction modes of operation," IET Power Electron. vol. 8, no. 8, pp. 1473-1482, 2015.

[28] R. R. Gopi and S. Sreejith, "Converter topologies in photovoltaic applications-A review," Renewable Sustain. Energy Rev., vol. 54 pp. 1-14, 2018.

[29] M. Veerachary, "Power tracking for nonlinear PV sources with coupled inductor SEPIC converter," IEEE Trans. Aerosp. Electron. Syst., vol. 41, no. 3, pp. 1019-1029, Jul. 2005.

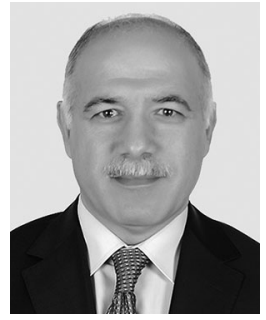

Hasan Komurcugil (S'94-M'99-SM'12) received the B.Sc., M.Sc., and Ph.D. degrees from Eastern Mediterranean University (EMU), Famagusta, Turkey, in 1989, 1991, and 1998, respectively, all in electrical engineering.

$\mathrm{He}$ is currently a full-time Professor with the Computer Engineering Department, EMU. His research interests include power electronics and innovative control methods for power converters.

Prof. Komurcugil is an Associate Editor for the IEEE TRANSACTIONS ON INDUSTRIAL ELECTRONICS and IEEE TRANSACTIONS ON INDUSTRIAL INFORMATICS.

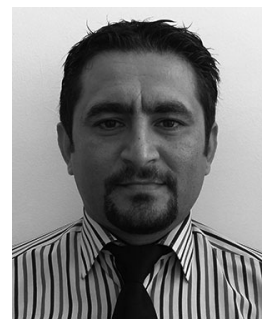

Samet Biricik (M'12-SM'19) received the B.Sc., M.Sc., and Ph.D. degrees in electrical and electronic engineering from Near East University, Nicosia, Turkey, in 2006, 2009, and 2013, respectively.

$\mathrm{He}$ is currently a Lecturer with the Department of Electrical and Electronic Engineering, European University of Lefke, Lefke, and a Research Fellow with the School of Electrical and Electronic Engineering, Technological University Dublin, Dublin, Ireland.

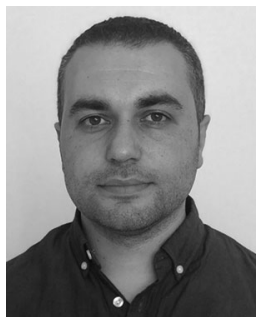

Naki Guler received the B.Sc., M.Sc., and Ph.D. degrees in electrical and electronic engineering from Gazi University, Ankara, Turkey, in 2010, 2012, and 2019, respectively.

$\mathrm{He}$ is currently a Lecturer with the Electrical and Energy Department of Gazi University. His current research interests include control and applications of power electronic converters, energy conversion, and energy management of renewable sources. 